\title{
CONSTRUCTION MATERIALS FLOW INVESTIGATION - DELAY EVALUATION IN A SAND SUPPLY CHAIN WITH SIMULATION
}

\author{
Phelipe V. Ruiz ${ }^{1}$ and Patricia S.P. Fontanini ${ }^{2}$
}

\begin{abstract}
The construction sector is considered one of the largest resource consumers on the planet and one of the main productive sectors of the economy. This scenario justifies the study of the flow of materials used in the construction, from the systematization of its processes, to reduce waste and improve the processes involved. This research aims to develop a simulation model of a residential building sand supply chain with the application of the delay meter and its monetary impacts on the enterprise. The impact of delays in the flow of the supply chain was analyzed and verified through a series of simulations. The application of the Lean Construction principles and the possibilities of theoretical simulation with the use of the solutions proposed by the researchers stand out. The proposed model demonstrates the impacts arising from delays in the delivery of materials, leading to the stoppage of teams and the accumulation of work. This scenario leads to the delay in the delivery of the project or the need to increase the team to achieve the productivity rates necessary to mitigate the existing delays. The model structure used in this study has potential for implementation in other construction supply chains.
\end{abstract}

\section{KEYWORDS}

Lean construction, process, flow, simulation, supply chain management

\section{INTRODUCTION}

Increasing competition in today's market and decreasing profit margins create the need for more significant investment in planning and control, leading to studies to find solutions that reduce waste and losses in the sector. Supplies chain in construction tends to be fragmented due to the large variety of projects, suppliers, and other direct (such as a workforce) and indirect (equipment rental) resources required.

The common understanding of project management is time-dependent, traditional strategies, policies, and guidelines for building supply chain management have been based on temporary approaches. In this sense, the problems encountered in construction supply chains can be attributed to the combined impact of increased fragmentation and inefficient management methods (Honório et al. 2014).

Economic globalization has promoted significant transformations in the world economy. Examples of these transformations are the increased competitiveness, the

1 PhD Student, Civil Engineering, Architecture, and Urbanism Department, Campinas State University, Campinas, CEP 13083-889, Brazil, phelipevruiz@gmail.com, orcid.org/0000-0003-3092-1276

2 Professor, Civil Engineering, Architecture, and Urbanism Department, Campinas State University, Campinas, CEP 13083-889, Brazil, pspucha@gmail.com, orcid.org/0000-0002-7532-7505 
introduction of new management technologies and behavioral change in the consumer market, which is becoming increasingly demanding and informed. In the last decade, Brazilian civil construction has been undergoing a process of changes and productive restructuring in several segments.

This new economic scenario led companies willing to remain in the competitive market to seek new positions and improvements in their production and management chains, trying to understand the supply chain as a whole, looking for ways to minimize costs, deadlines, and waste. Reasons for a decline in construction productivity include: management failure to provide necessary tools, material, instruction, training, and schedules to allow work to be completed without delays, shortages, and cost overruns (Enshassi et al. 2005; Korb et al. 2019).

One of the main focuses of supply chain studies today is to understand the lean mindset applied to the agent system, where the main objective is to make Lean concepts viable in the supply chain logistics structure. Despite several studies to understand and implement Lean mentality in the construction supply chain, through the application of Lean mentality principles, there are still few advances, considering the complexity of the investigated supply chains (Fontanini et al. 2008).

The principles of Lean thinking meet the demands of the current context and have as their starting point the elimination of waste. Lean supply systems require integration into the production process, which means minimizing waste. Integration allows better synchronization between supply and demand, bringing material to the workplace. (Azambuja et al. 2013). The purpose of this study is to evaluate the effects of using a delay generation system on the construction order time and delivery interval in a sand supply chain, measuring the impacts from supplies chain model simulations.

\section{SUPPLY CHAIN AND MATERIALS FLOW}

By definition, the supply chain is the process of moving goods from customer order through the stages of raw material procurement, production to distribution of products to customers. The Construction Supply Chain (CSC) differs in many ways from its manufacturing counterpart. Its structure is fragmented. Information flow crosses companies slowly, and little information is shared among them, where competitive practices are quite frequent, and there is a need for management tolerance standardization across supply chains (Azambuja and O’Brien 2009).

The CSC commits many organizations and encompasses a large set of activities with a higher level of complexity. Such activities occur basically in three streams, called information flow, capital flow, and material flow (Luhtala et al. 1994). There are different interfaces to connect these flows, which are the links between contractors, suppliers, and concurrent projects. Proper supply chain management in construction is necessary, as owners cannot fully achieve project objectives without relying on contractors and suppliers (Azambuja and O'Brien 2009).

Research in the field of Lean Construction techniques and applications are still under study. Several researchers in Brazil and worldwide have sought the development of this approach. From a long-term perspective, building organizations need to improve processes to find and use best practice continually. However, even best practice has a large reserve of potential improvement and efficiency, or at least it continues to evolve (Soto 2008).

Material flow management is interested in obtaining information about the process under study through further analysis and using this data to further improve operations. 
This flow management can be implemented through time-consuming processes to locate where problems are (Surveski 2013).

\section{MODELING AND SIMULATION}

In the quest to improve production flows, it is possible to implement improvements in both productivity and quality when resources are correctly used. However, the risks and responsibilities involved in making a decision can be an impediment for managers to offer suggestions based on their knowledge, ideas, and creativity. Simulation is an excellent tool to overcome this impediment because, with the possibility of analyzing a new proposal through a simulation model, it is possible to test the impact of the suggestions, which is important to sell the idea of changes to decision-makers (Montevechi et al. 2007). The simulation allows you to create the supply chain in a virtual environment and perform various tests on it. This allows to compare the multiple results obtained and, thus, arrive at the most efficient production model.

The simulation allows you to create a supply chain in a virtual environment and test different scenarios. This allows comparing the multiple results obtained and arrive at the production model that best meets the company's demand.

When thinking about simulating something, one tries to affect a system, a grouping of parts that work together, aiming at a common goal. A system always assumes a causeeffect interaction between its components (Chwif and Medina 2015).

Simulation models were created to allow the understanding of the application of the Lean project in construction. Simulation models have become an experimentation tool, in which Lean principles have been introduced to assess their impacts on simpler processes (Al-Sudairi 2007).

In the simulation, the flow is the rate of change of stock. For example, in a manufacturing company, the business process center revolves around the flow of orders, materials, skilled labor, machinery, and money. The stock of material, for example, determines the stock level maintained by the company, where the stock level decreases with the product's shipping rate and increases with the production rate.

When mapping the construction chain determining the activities and their cycle times, the behavior of the process is identified. It is still possible to make a comparison between an initial model and a Lean model, drawing on them a strategy that interprets the results obtained, evaluating the current state and the future state (Al-Sudairi 2007; Azevedo 2010).

\section{RESEARCH METHOD}

In the model presented in this article, the sand flow was evaluated in a case study of the construction of a $300 \mathrm{~m}^{2}$ single-family residential building. The development of the simulation model of this study was based on the works of Ruiz, Fontanini and Corrêa (2019) and Ruiz and Fontanini (2014). The period between the first and last request for sand delivery was 300 days. Shipments were weekly, made in a $6 \mathrm{~m}^{3}$ truck. The ordering interval for sand work was, on average, two days, and the delivery time was three days.

With this information, a computational model was elaborated in the Stella ${ }^{\circledR}$ software, simulating the work scenario. Within the model was inserted a delay system, that influenced the order and delivery intervals and an accountant. The collected data allowed the visualization of the impact for the construction. The delays during the simulation varied randomly. 
As for the delay in the work order interval, a maximum tolerance of 1.5 days in a month was considered, therefore with the delay system ranging from 0 to $5.00 \%$ in the observed delivery times. Regarding the delay in the restoration interval, the tolerance was two days late in one month, which resulted in a 0 to $6.66 \%$ variation in its delay generation system. These grace periods were considered based on observations of the actual case study arrears.

A bricklayer and three mason's assistant s formed the impacted labor. The personhour value was obtained from TCPO BIM 2019 (Tabela de Composições e Preços para Orçamentos - Table of Compositions and Prices for Budgets). This application establishes the base cost for construction workers. Mason's assistant receives the amount of 7.9700 $\mathrm{R} \$ / \mathrm{hr}(\sim 1.57 \mathrm{US} \$ / \mathrm{hr})$, and for masons, the amount of $\mathrm{R} \$ 6.5500 / \mathrm{hr}(\sim 1.92 \mathrm{US} \$ / \mathrm{hr})$. The 2019 social and legal charges of $115.7900 \%$, defined by SINAPI (Sistema Nacional de Preços e Índices - National Price and Index System), was added to the amount received by the workers. The dollar price used refers to the 17th of January in the amount of $\mathrm{R} \$ 4.1600$.

A total of 100 simulations were performed on the model. The generated data were evaluated for the mean, median, standard deviation, coefficient of variation, amplitude, maximum, and minimum values. Based on this assessment, the impact of delays was measured on both the expected total Lead Time and the costs relative to the waiting teams. This research used the Stella ${ }^{\circledR}$ software version 9.1.2 for the simulations and Microsoft Office Excel 2016 for the statistical analysis.

\section{DELAY IMPACTS}

The structuring of the production flow started by collecting the ordering and delivery intervals for the sand. The sand supply chain data from construction were analyzed, from the execution of the foundations to the finishing. This supply chain has been digitally recreated using programmable inventory and flow functions. The delay generator was included in this flow, randomly impacting the order and delivery intervals.

After completing the supply chain modeling, it was verified as to its functioning, comparing the results generated with the data of the case study. With the model developed, shown in Figure 1, 100 simulations were performed, and their data related to the damage caused transferred to the Microsoft Office Excel software. After releasing the simulation data, the mean, median, standard deviation, coefficient of variation, amplitude, maximum, and minimum values were calculated (Table 1).

Table 1: Impact of cost delays (loss)

\begin{tabular}{ccccccc}
\hline $\begin{array}{c}\text { Average } \\
(\boldsymbol{\mu})\end{array}$ & $\begin{array}{c}\text { Standard } \\
\text { deviation } \\
(\mathbf{s})\end{array}$ & Median & $\begin{array}{c}\text { Coefficient } \\
\text { of variation }\end{array}$ & Maximum & Minimum & Amplitude \\
US\$ & US\$ & US\$ & $\%$ & US $\$$ & US\$ & US\$ \\
\hline $1.993,78$ & 51,08 & $1.994,06$ & 2,5621 & $2.140,37$ & $1.872,45$ & 267,91 \\
\hline
\end{tabular}

The results obtained in the simulations were applied to a dispersion graph, as shown in Figure 2. The analysis of this information was ordered and organized in the form of a table, as shown in Table 2, which shows the range of results and the number of occurrences from a Loss value in Dollars. 


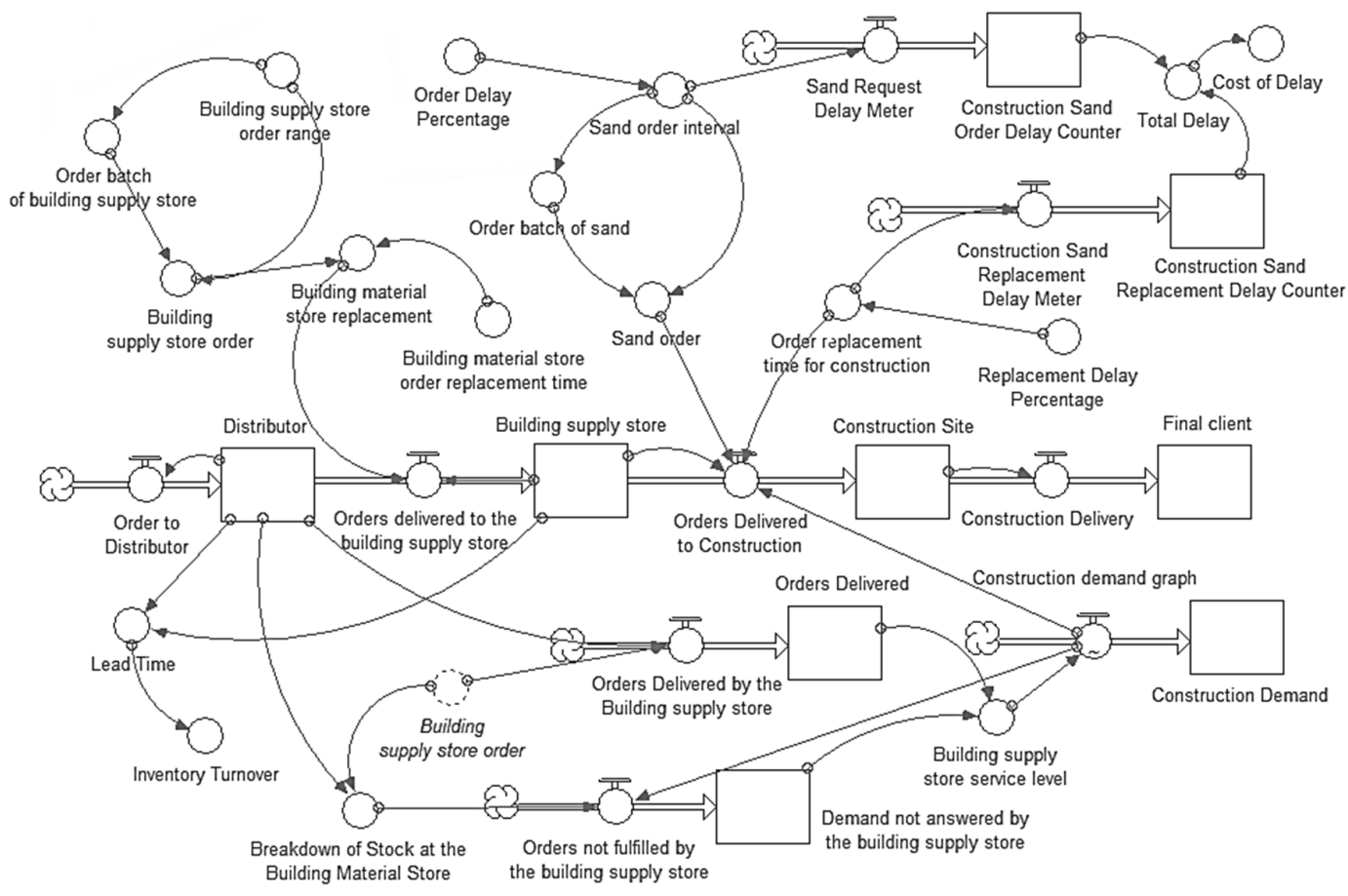

Figure 1: Macro Model of Sand Supply Chain Value Flow Map with a Delay and Loss Accounting System

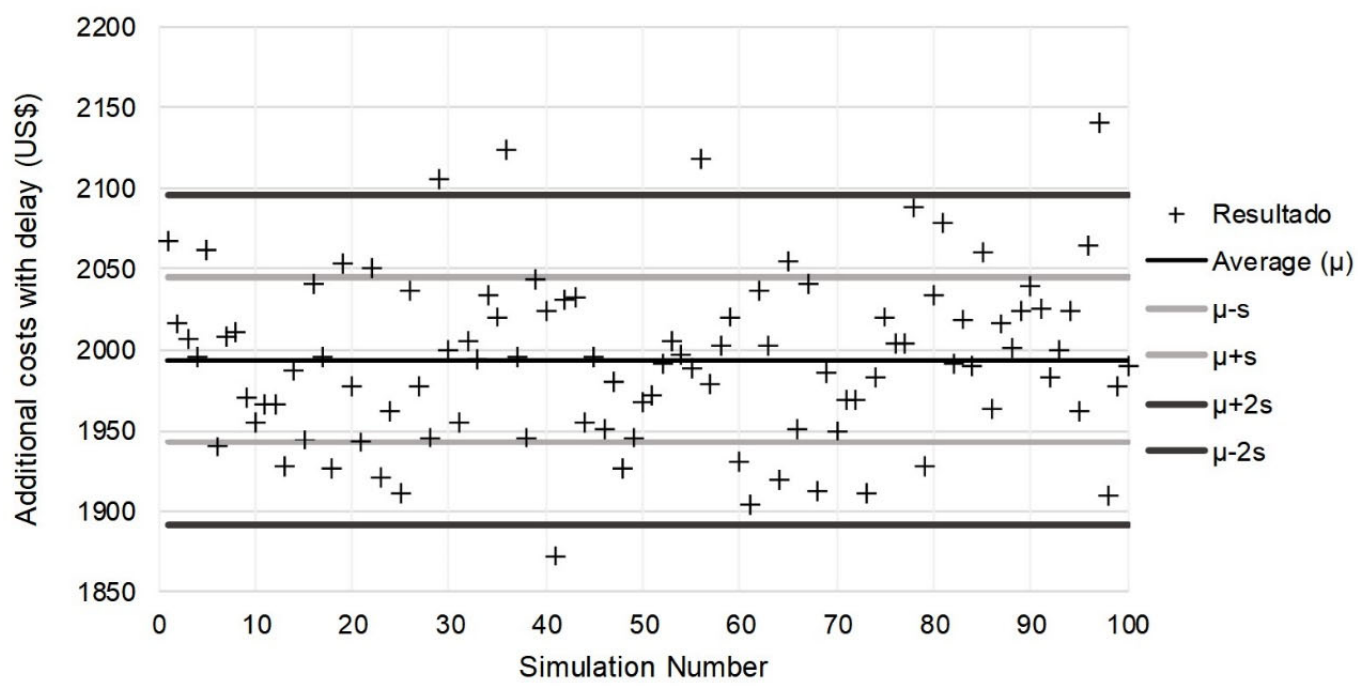

Figure 2: Graph of the dispersion of losses about the number of the simulation

Figure 3 shows the relationship between losses and the frequency of occurrence within the model. Through the visual analysis, it was possible to verify that even with the simulations using a system of variation of random delays, at the end of the analysis a behavior was perceived in the obtained data. An equation was developed that allows a quick assessment as to the frequency of occurrence of the simulated data when launching the value of Loss of interest. 
This equation was able, with a high degree of precision, to indicate the behavior of the simulated results, as shown in Table 3. However, to ensure the accuracy of the equation, it was necessary to use a large number of decimal places in its coefficients. Table 3 presents these coefficients for better visualization.

Table 2: Evaluation of the results obtained

\begin{tabular}{|c|c|c|}
\hline $\begin{array}{c}\text { Loss } \\
\text { US\$\$ }\end{array}$ & $\begin{array}{c}\text { Coverage } \\
(\%)\end{array}$ & $\begin{array}{c}\text { No. of } \\
\text { Occurrence }\end{array}$ \\
\hline $1.899,25$ & 1 & 1 \\
\hline $1.926,04$ & 9 & 8 \\
\hline $1.952,83$ & 22 & 13 \\
\hline $1.979,62$ & 39 & 17 \\
\hline $2.006,41$ & 65 & 26 \\
\hline $2.033,20$ & 79 & 14 \\
\hline $2.059,99$ & 91 & 12 \\
\hline $2.086,79$ & 95 & 4 \\
\hline $2.113,58$ & 97 & 2 \\
\hline $2.140,37$ & 100 & 3 \\
\hline
\end{tabular}

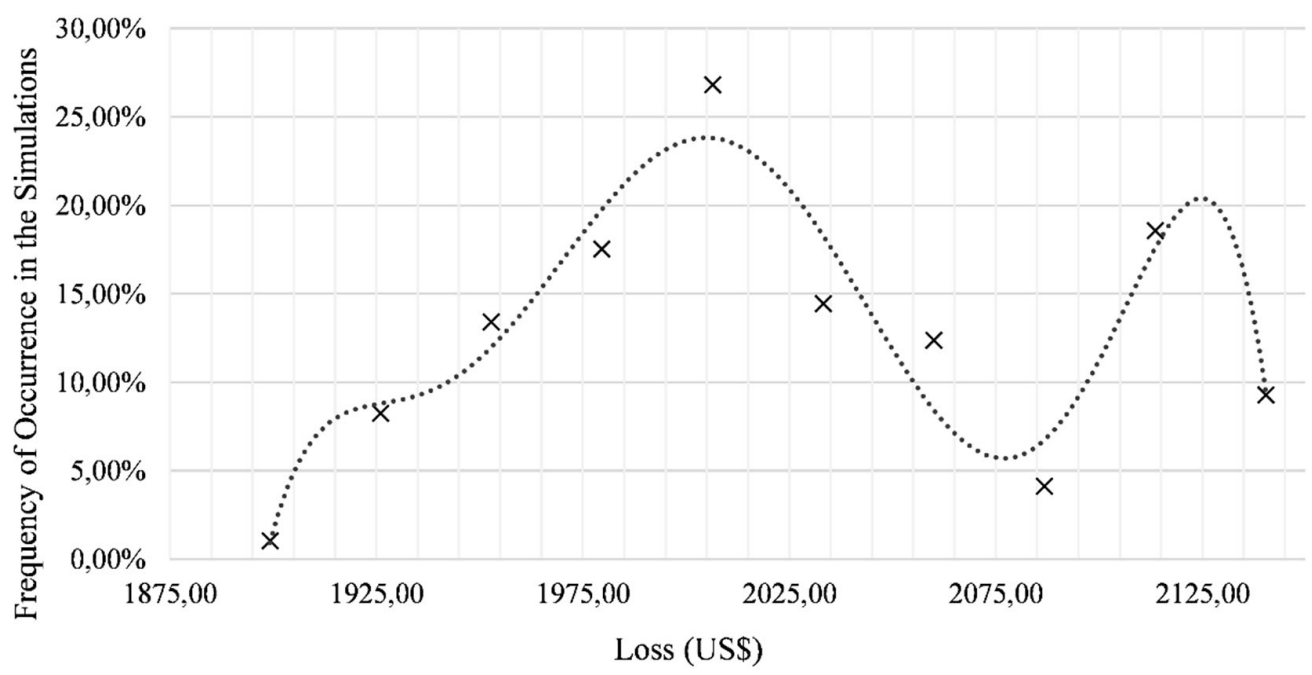

Figure 3: Loss frequency graph

Through the analysis of these data, a relationship of coverage of the results with loss was obtained (Figure 4). Using this graphical analysis, elaborate a correlated equation for data coverage and loss, showed in Table 2. Using a desired scope, it is possible to calculate the possible loss. This equation freed up more help for making difficult decisions, quickly evaluating or impairing average performance during the execution of a limited percentage. 
Table 3: Frequency equation and its coefficients

\begin{tabular}{cc}
\hline \multicolumn{2}{c}{ Frequency Equation } \\
\hline Frequency $=a \cdot x^{6}+b . x^{5}+c . x^{4}+d . x^{3}+e . x^{2}+f \cdot x+g$ \\
\hline Equation Coefficients \\
\hline b & $-2,760890271283 E-16$ \\
c & $1,142845517184 \mathrm{E}-11$ \\
$d$ & $-1,970356316063 \mathrm{E}-07$ \\
e & $1,811054511415 \mathrm{E}-03$ \\
$\mathrm{f}$ & $-9,359924794248 \mathrm{E}+00$ \\
$\mathrm{~g}$ & $2,578958470246 \mathrm{E}+04$ \\
\end{tabular}

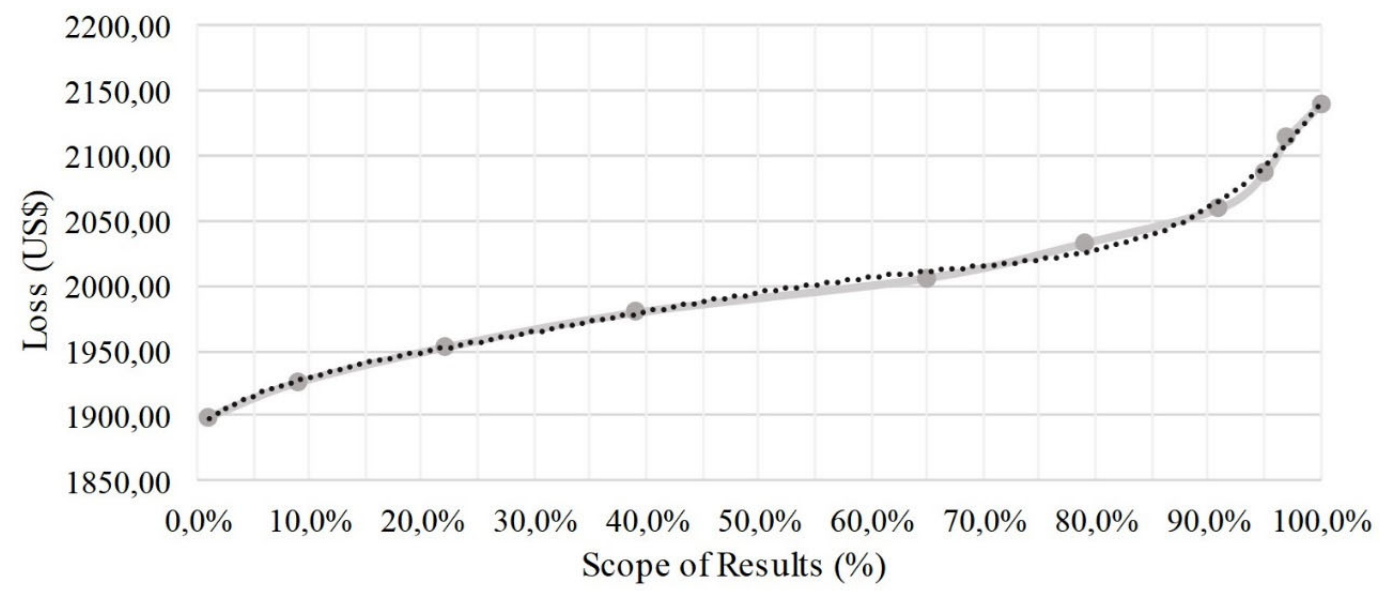

Figure 4: Graph of the scope of results for losses

Table 4: Loss equation and its coefficients

\begin{tabular}{|c|c|}
\hline \multicolumn{2}{|c|}{ Loss Equation } \\
\hline \multicolumn{2}{|c|}{ Loss (US $\$$ ) $=\mathrm{a} \cdot \mathrm{x}^{5}+\mathrm{b} \cdot \mathrm{x}^{4}+\mathrm{c} \cdot \mathrm{x}^{3}+\mathrm{d} \cdot \mathrm{x}^{2}+\mathrm{e} . \mathrm{x}+\mathrm{f}$} \\
\hline \multicolumn{2}{|c|}{ Equation Coefficients } \\
\hline $\mathrm{a}$ & $3,064920343399 \mathrm{E}+03$ \\
\hline $\mathrm{b}$ & $-6,666296135139 \mathrm{E}+03$ \\
\hline $\mathrm{c}$ & $5,351318941387 \mathrm{E}+03$ \\
\hline$d$ & $-2,018721182116 \mathrm{E}+03$ \\
\hline $\mathrm{f}$ & $5,152225019053 \mathrm{E}+02$ \\
\hline
\end{tabular}

\section{CONCLUSIONS}

Through the statistical analyses carried out in this study, it was possible to evaluate the effectiveness and precision of the model elaborated with a close approximation to reality. The study allowed the visualization of the impact of the delays with greater clarity and a 
better understanding of their behavior with considerable damage. It was possible to verify the significant influence that the delays cause on the flow of residential construction and the harmful effects of the absence of a system stock and supply control. In the case study, the average loss generated by delays within the sand supply chain for the single-family residential project was R $\$ 6251.39$ (US\$ 1742.30). The model considered only the costs related to labor. The impact of material delays was not assessed in this study.

Due to the absence of a control system over orders and delays, it would be necessary to consider an additional cost in the work of approximately R $\$ 6543.00$ (US\$ 1823.58) in addition to the price initially foreseen, to cover $95 \%$ of possible losses. Through the analyses performed, it was observed that the range of results regarding the loss at the end of the simulations was approximately R $\$ 840.00$ (US\$ 234.11), almost equivalent to hiring another mason's assistant.

Such findings demonstrate the importance of having an inventory control system, which would allow for the ordering of materials in advance, before they are exhausted, and of having a control and evaluation system for their suppliers, which would guarantee on-time deliveries, thus minimizing impacts and losses on the supply chain and increasing the efficiency of the system.

Applying such controls, it would be possible to stay within the cost initially provided for in the project. In addition to the direct impacts caused by the delays, the other financial consequences resulting from this situation must be taken into account, since, with these delays, there will be a consequent decrease in the profit margins previously stipulated, and the amount of the loss could be used for purchase.

Due to the study carried out, allied to the current competitive market, the decrease in profit margins obtained and less money invested, there is a need for more significant investment in the areas of planning and control and new tools and methodologies to address this issue. There is, therefore, a need to seek solutions that provide for problems and that allow actions to eradicate or mitigate the delays and losses caused, as discussed in this article. This demonstrates the importance of being prepared and anticipating future problems, placing the most prepared companies ahead of their competitors.

The model structure used in this study has potential for implementation in other construction supply chains. A proposal for future studies would be to implement this model in other flows, assessing the impacts of delays in the monetary sphere. With this information, it is possible to better assess the risks and aid decision making, allowing for better based planning. Another proposal for future studies is the analysis of a model that involves the evaluation of the damage caused on a chain belonging to a system of simultaneous chains, with the implementation of delays and the assessment of the indirect impacts on the dependent chain, evaluating its forms of interaction.

\section{ACKNOWLEDGMENTS}

We would like to thank the State University of Campinas for the support and provision of the necessary infrastructure to conduct this research.

\section{REFERENCES}

Al-Sudairi, A.A. (2007). "Evaluating the effect of construction process characteristics to the applicability of lean principles." Construction Innov., J. Yang (ed.), 7(1), 99-121. Azambuja, M. and O’Brien, W.J. (2009). Supply Chain Modeling: Issues and Perspectives. Construction supply chain management handbook, CRC Press, New York. 
Azambuja, M., Schnitzer, T., Sahin, M., and Lee, F. (2013). "Enabling lean supply with a cloud computing platform an exploratory case study." Proc. $21^{\text {st }}$ Ann. Conf. Int. Group for Lean Construction, Fortaleza, Brazil, pp. 205-214.

Azevedo, V. da S. de. (2010). "Planejamento de Atividades da Construção Predial Visando a Redução de Perdas de Processo na Ótica da Construção Enxuta." Dissertação (Mestrado em Engenharia Civil, Área de Concentração em Estruturas) Programa de Pós-Graduação em Engenharia Civil, Universidade do Estado do Rio de Janeiro, Rio de Janeiro, Brazil.

Chwif, L., and Medina, A.C. (2015). Modelagem e Simulação de Eventos Discretos: Teoria \& Aplicações. Elsevier, Rio de Janeiro, Brazil.

Enshassi, A., Mohamed, S., Mayer, P., and Abed, K. (2005). "Contractors perspective toward factors affecting labor productivity in building construction." Int. J. of Productivity and Performance Management, 56, 446-460.

Fontanini, P.S.P., Picchi, F.A., Loureiro, S.A., Lima, O.F., and Folch, A.T. (2008). "Simulating a construction supply chain- preliminary case study of pre-cast elements." Proc. 16th Ann. Conf. Int. Group for Lean Construction, pp. 371-380.

Honório, R. T., Da Costa, J.M.C., and Serra, S.M.B. (2014). "Evaluation of supply and service of steel assembly of structures." Proc. 22nd Ann. Conf. Int. Group for Lean Construction, pp. 1057-1068.

Korb, S., Telyas, A., Sacks, R., and Duka, A. (2019). "Evaluating Multiskilling in Residential Construction Projects Using Regional Industry Simulation." Proc. 27th Ann. Conf. Int. Group for Lean Construction, pp. 1229-1240.

Luhtala, M., Kilpinen, E., and Anttila, P. (1994). LOGI: Managing make-to-order supply chains. Helsinki University of Technology, Finland.

Montevechi, J. A. B., Pinho, A. F. De, and Leal, F. (2007). "Application of Design of Experiments on the Simulation of a Process in an Automotive Industry." Winter Simulation Conference, 39, Washington, DC, 1601-1609.

Ruiz, P. V., and Fontanini, P.S.P. (2014). "Avaliação Do Planejamento De Fluxos De Materiais No Setor Da Construção Civil.” (Evaluation of Material Flow Planning in the Civil Construction Sector) XV Encontro Nacional de Tecnologia do Ambiente Construido, 1478-1487.

Ruiz, P.V., Fontanini, P.S.P., and Corrêa, F.R. (2019). "Materials flow investigation: An aluminum frames supply chain simulation." Int. Review on Modelling and Simulations, Praise Worthy Prize S.r.1, 12(1), 30-36.

Soto, L. (2008). "Construction design as a process for flow." Massachusetts Institute of Technology, Cambridge, Mass., USA.

Surveski, R. (2013). "Materials Lead Time Reduction in a Semiconductor Equipment Manufacturing Plant: Process Flow Planning." Massachusetts Institute of Technology, Cambridge, Mass., USA. 